\title{
THE HIGH SPEED MACHINING OF METALS USING
}

\section{CRYOGENIC TREATMENT}

\author{
PRABAHARAN. T ${ }^{1}$ \& KARTHIK PANDIYAN. $\mathbf{G}^{\mathbf{2}}$ \\ ${ }^{1}$ Senior Professor, Department of Mechanical Engineering, Mepco Schlenk Engineering College, \\ Sivakasi, Tamil Nadu, India \\ ${ }^{2}$ Department of Mechanical Engineering, Sri Vidya College of Engineering and Technology, \\ Virdhunagar, Tamil Nadu, India
}

\begin{abstract}
In customary fast machining forms unreasonable warmth is created amid the chip arrangement process, which expands the temperature of cutting apparatus and quickens device wear. Traditionally slicing liquid is utilized to cool and grease up cutting procedure. It ought not to encourage longer device life, higher cutting velocity, better work surface, less developed edge, less demanding chip breaking and lower creation cost. To amend this issue cryogenic treatment of metals is carried on to accomplish instrument life profitability. Cryogenic machining utilizes fluid nitrogen as a coolant. Fluid Nitrogen has a breaking point of - 199 degree centigrade. It has been watched that at cryogenic temperature device materials get harder and more grounded. A smaller scale spout is framed between apparatus face and chip breaker and LN2 has gone through it. The chip breaker lifts chip with the goal that the fly achieves the most blazing spot i.e. device chip interface. Now LN2 retains warmth and dissipates creating gas pad causing grease impact. This limited cryogenic cooling decreases the device confront temperature, upgrades its hardness, and the oil impact lessens contact and device wear. Cryogenic machining wipes out the developed edge issue on devices for chilly temperature diminishes plausibility of chips welding to the tool. This paper uncovers the correlation of cryogenic machining with traditional process in the parts of hardware life, profitability, and generation cost.

KEYWORDS: Cryogenic Machining, Liquid Nitrogen, Temperature of Cutting Tool, Tool Chip Interface, Tool Life Productivity \& Tool Wear
\end{abstract}

Received: Sep 18, 2018; Accepted: Oct 08, 2018; Published: Nov 30, 2018; Paper Id.: IJMPERDDEC201864

\section{INTRODUCTION}

In traditional machining forms when we go for fast exorbitant warmth is produced amid the chip arrangement process, which expands the temperature of cutting device and quickens instrument wear. Routinely slicing liquid is utilized to cool and grease up cutting procedure, thereby lessening apparatus wear and expanding device life. However, traditional cooling process has characteristic wellbeing and ecological issues. Dumping of cutting liquid waste causes natural contamination, regardless of whether we fall back on reusing of cutting liquid waste it would cost twofold the price tag. Regular coolant postures medical issues to specialist, similar to Dermatitis and skin malignancy. Cryogenic treatment to accomplish longer device life, higher cutting velocity, better work surface, less developed edge, simpler chip breaking and lower generation cost and which considers previously mentioned wellbeing and ecological issues. 
Cryogenic machining is one such process in which previously mentioned highlights are available. Cryogenic machining utilizes fluid nitrogen as a coolant. Fluid Nitrogen has a breaking point of $-199^{\circ} \mathrm{C}$.

\section{CRYOGENIC MACHINING METHODOLOGY}

The cryogenic properties of the both work piece materials and instrument materials were examined. Those investigations presumed that it isn't attractive to cool the work piece for three reasons

- Metals tend to increment in hardness and quality at cryogenic temperature

- $\quad$ Presenting the work piece to low temperatures may expand the scraped area to the cutting device.

- The investigation of cryogenic properties of regular apparatus materials (E.g. fast steel and different evaluations of carbides) demonstrates the upsides of cooling the apparatus.

At cryogenic temperatures, the device will get harder and more grounded. Effect testing demonstrates that the device materials don't discernibly change in fragility, nor do they crack all the more effortlessly. Because of material examinations, it is prescribed that the cutting instruments, yet not the work piece materials, be cool.

The cryogenic machining approach has following concepts.

- Cryogenic liquid is connected specifically to, and just to, the very tip of the cutting instrument, where the material is being cut and warmth is being created. The cooling power isn't squandered on any superfluous regions.

- Using the vitality adjust idea, the flow rate of the cryogenic liquid is in the extent to the warmth produced in the cutting procedure. The work piece will keep up steady temperature and not subjected to dimensional error and geometrical mutilation.

- The smaller scale spout is shaped between the device face and chip breaker as a business new cutting instrument get together, a plan that is temperate and advantageous for clients.

In light of the ideas the cryogenic machining cooling standards utilizing a level cutting supplement with a hindrance chip breaker as illustration LN2 is discharged through a spout between the chip breaker and the substance of the instrument embed. The chip breaker lifts up the chip so LN2 can achieve the apparatus chip interface. This vital component enables LN2 to cool the most sweltering spot intently and the stream not obstructed by the chip. Now, LN2 ingests the warmth, dissipates rapidly, and shapes a liquid/gas pad between the chip and device confront along these lines giving "Oil impact".

\section{PRINCIPLE OF ECONOMIC CRYOGENIC MACHINING}

This confined cryogenic cooling diminishes the device confront temperature, upgrades its hardness, thus lessens its wear rate. The oil impact additionally decreases the rubbing and apparatus wear. The device body stays intense, as it isn't cooled straight forwardly. This is the best route for long instrument life while minimal sum on LN2. This approach enhances chip softening up three ways: embrittle the chip by icy temperature, enhance chip grain structure bylesseningauxiliarydistortion and recrystallisation, and twist the chip with the chip breaker. This new cryogenic machining approach kills the development edge issue (BUE) on instruments on the grounds that the frosty temperature decreases the likelihood of chip welding to the device. The high-weight cryogenic stream additionally evacuates 
conceivable BUE.

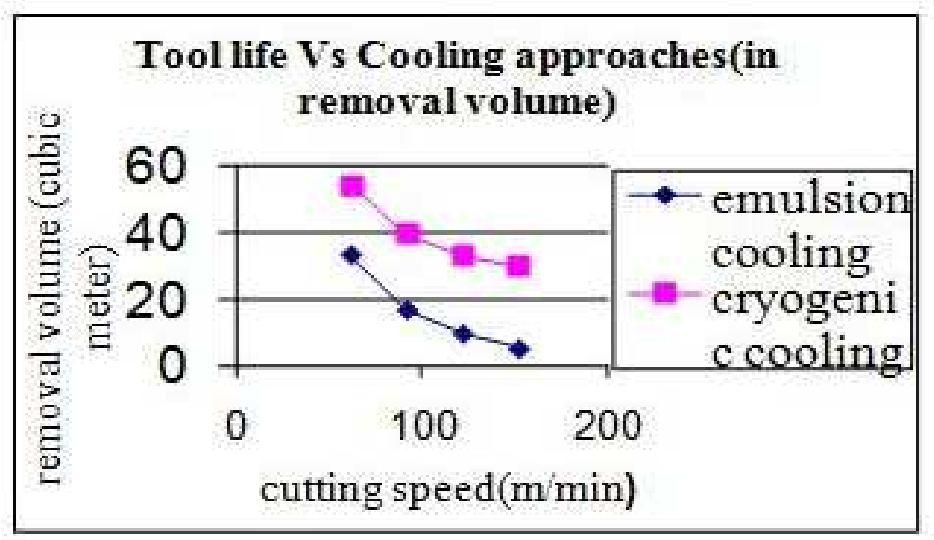

Figure 1: Tool Life vs Cooling Approrach

This procedure will permit rapid cutting and no BUE, hence it will deliver better surface quality.

\section{TOOL LIFE COMPARISION WITH CONVENTIONAL MACHINING}

Machining titanium with a business cutting instrument embed called Kenna metal apparatus does near investigation of hardware life between cryogenic machining and ordinary emulsion cooling. While machining titanium, instrument life is most touchy to cutting velocity, however, it is likewise delicate to nourish and profundity of cut. A settled profundity of cut $(1.27 \mathrm{~mm})$ and sustain $(0.254 \mathrm{~mm})$ are chosen in view of the machining information handbook. The best cooling outcome and the best apparatus life is that utilizing both essential rake spout and helper flank spout. The area of the chip breaker with spout influences the viability of LN2 Infiltration into chip apparatus interface to give oil impact and cooling. Another investigation demonstrates the apparatus life can be enhanced 15\% to half. The best spout/chip breaker area was recognized in the test, around $1.7 \mathrm{~mm}$ from the front line.

The Instrument Life information i.e. volume expulsion verses speed appears in the figure. The apparatus life under cryogenic machining is surprisingly better than that got under high-weight water helped machining. The device life increments were more critical at higher cutting velocities. Longer apparatus life in cryogenic machining permits cutting material at higher paces.

The Taylor tool life equation for fixed speed and depth of cut is usually expressed as

$$
V T^{n}=C
$$

Where ' $T$ ' is the tool life in minutes, and ' $V$ ' the cutting speed in surface feet/min. The index ' $n$ ' depends upon the tool material, 'c' is cutting speed of tool life per min, function of work piece material strength and tool materials. To fit the test results in to the Taylor tool life equation, the tool life is plotted against the cutting speed in log-log scale as shown in figure. The following constants of equation were obtained

For emulsion coolant $\mathrm{n}=0.3214, \mathrm{c}=507$

For cryogenic machining $\mathrm{n}=0.5164, \mathrm{c}=1142$.

Carbide tool behaved as like a ceramic tool in cryogenic machining, while machining titanium, machinability improves in cryogenic machining as constant C increases from 506 to 1142. 


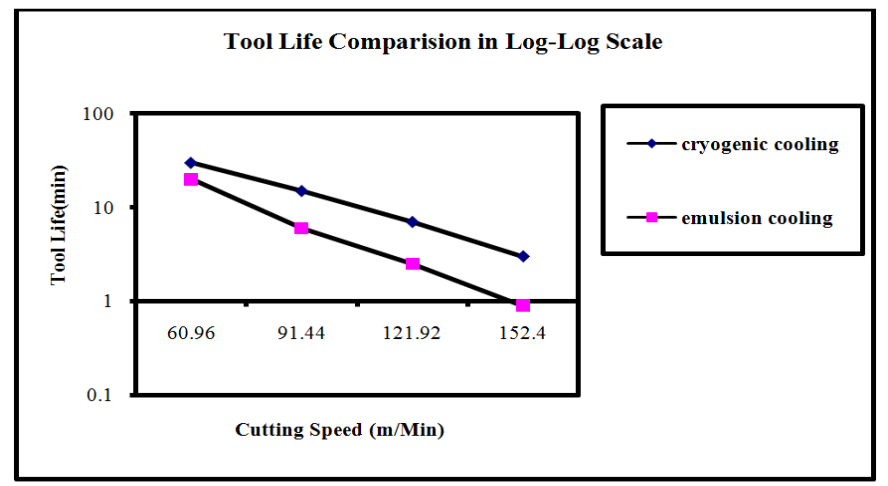

Figure 2: Tool Life vs Cutting Speed

\section{PRODUCTIVITY COMPARISON}

The time needed for making a part includes actual machining time, part loading/unloading time, and tool change time. For a fixed feed, depth of cut, and speed, the actual cutting would be the same for both conventional and cryogenic machining time. The time required to load and unload the part is fixed. Tool change time per part varies depending upon the tool life, as does the frequency of changing the tool. Actual machining time can be reduced if cutting speed is increased, but overall productivity may suffer from shorter tool life and an increase in time spent changing the tool. Therefore, the actual production rate is tied to improved tool life

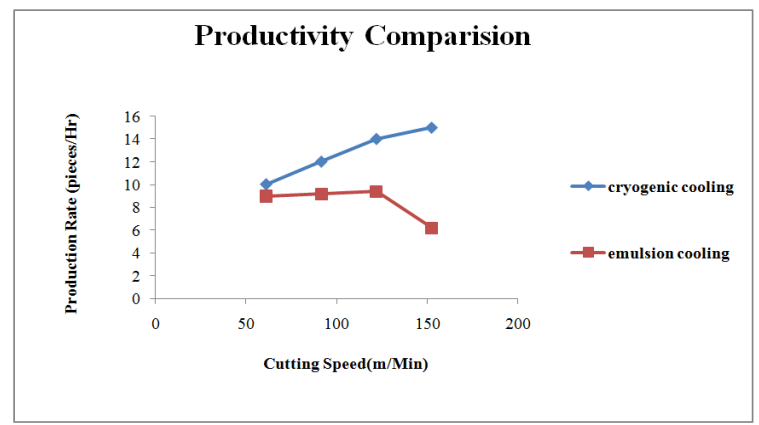

Figure 3: Productivity Rate vs Cutting Speed

The profitability of cryogenic machining is higher than traditional machining, and efficiency keeps on expanding as cutting pace increments. Regular machining efficiency significantly drops at high slicing speed because of quick instrument wear.

\section{PRODUCTION COST COMPARISION}

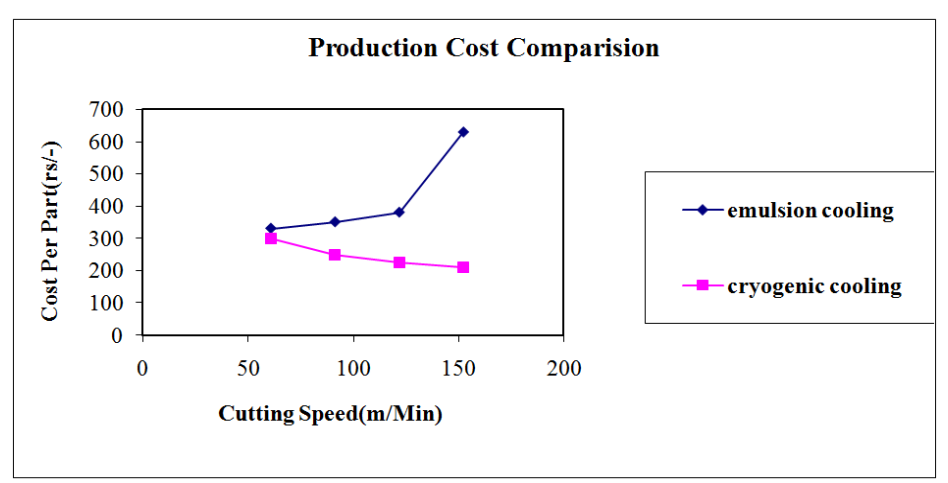

Figure 4: Production Cost 
The generation cost, aside from the work piece material cost, incorporates the machining cost, device cost and coolant cost. The generation cost examination between the cryogenic machining process and traditional emulsion cooling process appear in the figure. The aggregate cost is brought down for cryogenic machining in light of the fact that 1 . The device keeps going longer and 2. The cryogenic coolant cost is lower than regular emulsion cost. For all cutting velocities, cryogenic machining costs not as much as ordinary machining. For ordinary machining, the generation cost keeps on ascending as the cutting velocity expands, which clarify why titanium isn't cut at speeds higher than 200 or 300 feet/min. However at higher rates, the creation cost for cryogenic machining keeps on dropping, demonstrating that cryogenic machining has extraordinary focal points over customary machining at high speeds.

\section{CONCLUSIONS}

Limited concentration flying just to the cutting point, fluid nitrogen utilization is limited to a level less expensive than traditional coolant. From the apparatus life profitability and creation cost investigations, the new cryogenic machining approach demonstrates to have the accompanying preferences over customary emulsion cooling.

- Longer instrument life

- Better chip breaking and chip taking care of

- Higher efficiency.

- Lower generation cost

- Better work surface wrap up.

- $\quad$ Earth more secure.

- More beneficial for labourer.

\section{REFERENCES}

1. Akhbarizadeh, A., Golozar, M., Shafeie, A., \&Kholghy, M., (2008) "Effects of Austenizing Time on wear behaviour of D6 tool steel after deep cryogenic treatment" Journal of Iron and Steel Research, Vol. 16, 29-32

2. Baldissera, P., \&Delprete, C., (2009) "Effects of deep cryogenic treatment on static mechanical properties of $18 \mathrm{NiCrMo5}$ carburized steel" Journal of Materials and Design, 30 1435-1440.

3. Bhavar, V., Khot, S., Kattire, P., \& Singh, R. (2016) "Integrating deep cryogenic treatment with nitro-carburizing to improve performance of AISI H-13 tool steel" International Federation of Heat Treatment and Surface Engineering.

4. Chaudhari, B., Shekhawat, P., Ambeprasad, S. \& Kushwaha (2012) "Advanced Technology of Cryoprocessing for the Enhancement of Tool Material Machining Characteristics: A Review" International Journal of Emerging Technology and Advanced Engineering, ISSN 2250-2459, Volume 2, Issue 4.

5. Das, D., Dutta, A. K., \& Ray, K. K. (2009) "Optimization of the duration of cryogenic processing to maximize wear resistance of AISI D2 steel" Cryogenics, 49(5), 176-184.

6. Dhananchezian, M., Kumar, M. P., \& Rajadurai, A. (2009) "Experimental investigation of cryogenic cooling by liquid nitrogen in the orthogonal machining process"

7. Gill, S. "Optimization of cryogenic treatment to minimize the flank wear of AISI M2 high speed steel tools by taguchi technique" Journal of Engineering Research and Studies E-ISSN0976-7916, JERS, 3, 28-33. 
8. He, Y., Yang, K., WenshenQu, Kong, F., \& Guoyue Su., (2002) "Strengthening and toughening of a 2800-MPa grade maraging steel” Materials Letters 56, 763- 769.

9. Idayan, A., Gnanavelbabu, A., \& Rajkumar, K., (2014) "Influence of Deep Cryogenic Treatment on the Mechanical Properties of AISI 440C Bearing Steel” Procedia Engineering 97, 1683 - 1691.

10. Ilaiyavel, S., \& Sornakumar, T. (2011). “ToolLife Enhancement by Cryogenic Treatment” Journal of Microwave Science and Technology, 1(1-2).

11. Kaushal, A., Saluja, S. K., \& Rawat, R. S. S. (2015) “Effect of Cryogenic Treatment on Tool Steel (AISI D2)” International Journal of Research in Engineering and Technology, 4(1), 80-383.

12. Khandekar, S., Sankar, M. R., Agnihotri, V., \& Ramkumar, J. (2012)0” Nano-cutting fluid for enhancement of metal cutting performance" Materials and Manufacturing Processes, 27(9), 963-967.

13. Lal, D. M., Renganarayanan, S., \& Kalanidhi, A. (2001) "Cryogenic treatment to augment wear resistance of tool and die steels" Cryogenics, 41(3), 149-155.

14. Liu, S.T., Wu, X.C., Shi, L., Wu, Y.W. and Qu, W. (2015) "Influence of Cryogenic Treatment on Microstructure and Properties Improvement of Die Steel”. Journal of Materials Science and Chemical Engineering, 3, 37-46.

15. Molinari, A., Pellizzari, M., Gialanella, S., Straffelini, G., \& Stiasny, K. H. (2001) "Effect of deep cryogenic treatment on the mechanical properties of tool steels" Journal of materials processing technology, 118(1), 350-355.

16. Patil, N., Kakkeri, S., \& Sangamesh (2014) "Effect of cryogenic treated and untreated tool on its tool life-review" International Journal of Science and Research (IJSR) Volume 3 Issue 8

17. Pavan, K.M., Sachin, L.S., Mayur, S., Chandrashekar, A., \& Ajaykumar, B.S, (2014) "Effect of Cryogenic Treatment of the Mechanical and Microstructural Properties of Aluminium Alloys - A Brief Study" International Journal of Mechanical and Production Engineering, Vol-2

18. Taur, P. G., \& Sonawane, S. A. Analysis of Wear Resistance of Tool Steel After Deep Cryogenic Treatment.

19. Suchmann, P., Jandova, D., \& Niznaska, J. (2015) "Deep cryogenic treatment of H11 hot working tool steel" Journal of Achievements in Materials and Manufacturing Engineering 73/1 21-26.

20. Uygur, I., Gerengi, H., Arslan, Y., \& Kurtay, M. (2015) “The Effects of Cryogenic Treatment on the Corrosion of AISI D3 Steel" Materials Research, 18(3), 569-574.

21. Venses, G., \& Siva, R. S. (2015) "Optimisation of Deep Cryogenic Treatment Process on the Wear Resistance of 100 Cr6 Bearing Steel using Taguchi Technique” Journal of Advances in Mechanical Engineering and Science, 1(2), 9-20.

22. Yildiz, Y., Sundaram, M. M., Rajurkar, K. P., \& Nalbant, M. (2011) "The effects of cold and cryogenic treatments on the machinability of beryllium-copper alloy in electro discharge machining"

23. Zhirafar, S., Rezaeian, A., \& Pugh, M., (2007) "Effect of cryogenic treatment on the mechanical properties of 4340 steel" Journal of Materials Processing Technology 186 298-303. 